\title{
CORRIGENDUM
}

\section{Telomerized presenescent osteoblasts prevent bone mass loss in vivo}

K Yudoh and K Nishioka

Gene Therapy (2006) 13, 375. doi:10.1038/sj.gt.3302730

Correction to: Gene Therapy (2004) 11, 909-915. doi:10.1038/sj.gt.3302234

Since publication of the above article the authors have identified an error in Figure 2 of the above paper.

The correct figure is shown below.

The authors would like to apologise for this mistake.

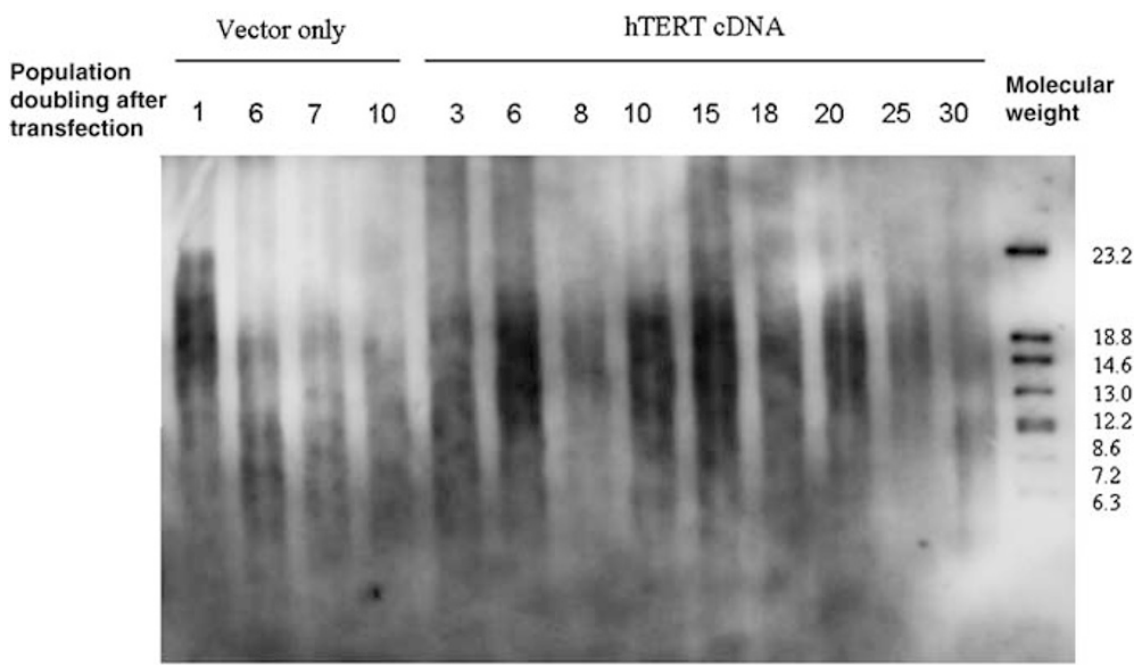

Figure 2 